\title{
Article \\ Photogrammetry (SfM) vs. Terrestrial Laser Scanning (TLS) for Archaeological Excavations: Mosaic of Cantillana (Spain) as a Case Study
}

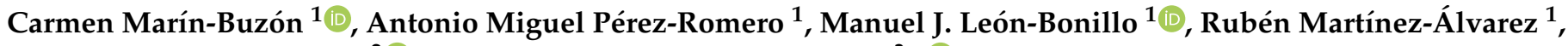 \\ Juan Carlos Mejías-García ${ }^{2}$ and Francisco Manzano-Agugliaro ${ }^{3, *(\mathbb{D}}$ \\ 1 Graphic Engineering Department, University of Sevilla, 41013 Sevilla, Spain; carmenmarin@us.es (C.M.-B.); \\ tao@us.es (A.M.P.-R.); leonbo@us.es (M.J.L.-B.); rbnmaral@us.es (R.M.-Á.) \\ 2 Prehistory and Archaeology Department, University of Sevilla, 41003 Sevilla, Spain; jcmejias@us.es \\ 3 Department of Engineering, CEIA3, University of Almeria, 04120 Almeria, Spain \\ * Correspondence: fmanzano@ual.es
}

Citation: Marín-Buzón, C.; Pérez-Romero, A.M.; León-Bonillo, M.J.; Martínez-Álvarez, R.; Mejías-García, J.C.; ManzanoAgugliaro, F. Photogrammetry (SfM) vs. Terrestrial Laser Scanning (TLS) for Archaeological Excavations: Mosaic of Cantillana (Spain) as a Case Study. Appl. Sci. 2021, 11, 11994. https://doi.org/10.3390/ app112411994

Academic Editor: Tung-Ching Su

Received: 25 November 2021 Accepted: 13 December 2021 Published: 16 December 2021

Publisher's Note: MDPI stays neutral with regard to jurisdictional claims in published maps and institutional affiliations.

Copyright: (c) 2021 by the authors. Licensee MDPI, Basel, Switzerland. This article is an open access article distributed under the terms and conditions of the Creative Commons Attribution (CC BY) license (https:// creativecommons.org/licenses/by/ $4.0 /)$.

\begin{abstract}
The discovery of a Roman mosaic from the 2nd century AD in Cantillana (Seville) generated interest and the need for exhaustive documentation, so that it could be recreated with real measurements in a 3D model, not only to obtain an exact replica, but with the intention of analyzing and studying the behavior of two main geomatics techniques. Thus, the objective of this study was the comparative analysis of both techniques: near object photogrammetry by SfM and terrestrial laser scanner or TLS. The aim of this comparison was to assess the use of both techniques in archaeological excavations. Special attention was paid to the accuracy and precision of measurements and models, especially in altimetry. Mosaics are frequently relocated from their original location to be exhibited in museums or for restoration work, after which they are returned to their original place. Therefore, the altimetric situation is of special relevance. To analyze the accuracy and errors of each technique, a total station was used to establish the real values of the ground control points (GCP) on which the comparisons of both methods were to be made. It can be concluded that the SfM technique was the most accurate and least limiting for use in semi-buried archaeological excavations. This manuscript opens new perspectives for the use of SfM-based photogrammetry in archaeological excavations.
\end{abstract}

Keywords: archaeology; photogrammetry; SfM; scanner; TLS; mosaic; marble

\section{Introduction}

In the 1980s, the Total Station without reflector (TPS) was introduced; in the 1990s GPS (Global Positioning System) [1] was introduced; at the beginning of the century, in the 2000s, LiDAR (Light Detection And Ranging or Laser Imaging Detection And Ranging) [2] was introduced. In the following decade, HDS (High Definition Surveying) emerged as a powerful technology in terms of speed, accuracy, accuracy, detail, and cost. This system is also often referred to as Terrestrial Laser Scanning (TLS), or sometimes as terrestrial LiDAR. However, it has yet to prove its advantages over current technologies.

The first commercial TLS system was built by Cyra Technologies in 1998 and was later acquired by Leica in 2001 [3]. TLS hardware has improved rapidly over the past two decades [4]. The price, size, and weight of laser scanners have fallen at a rapid rate, and the improvement of spatial resolution and measurement speed has also improved [5].

Instruments now classically known as TPS basically record single points individually, while TLS systems involve three-dimensional laser scanning that can record thousands of points per second of measurement [6]. With TLS, a point cloud is obtained that is similar to a photograph, but each point has coordinates $(X, Y, Z)$ and an associated color in the well-known RGB (Red, Green, Blue) format [7]. The main advantages of TLS systems are the high speed of data acquisition and the high level of detail linked to a very high 
theoretical accuracy. In summary, current TLS systems usually have a high millimeter spatial resolution, with an observation distance of tens of meters from the station, and the standard error is usually $\pm 2 \mathrm{~mm}$ at $25 \mathrm{~m}$ [8].

The first manuscript on the application of TLS for archaeology was fairly recent, according to the Scopus database, and dates from 2007 [9], where its possible use was suggested, but no archaeological work was performed. Later, in 2008, it was applied in an archaeological excavation in Egypt, and the results were combined with aerial photogrammetry [10]. These applications are slowly starting to be used, as is shown in the related literature. One application in 2009 [11] related to point cloud modeling, and demonstrated that it is a complex task to extract its unstructured information, requiring powerful software tools. In the 2010s, TLS was mostly used for archaeological applications in caves, such as in the Upper Paleolithic cave of Parpalló in Gandía [12], or in the Bronze Age cave "les fraux", in Perigord (France) [13].

Regarding the comparison between both methods, it is worth mentioning studies carried out in 2002 comparing TLS and SfM photogrammetry, usually in optimal conditions for the recording of cultural heritage, and that both methods obtained similar results [14]. Only in 2012 was TLS compared with terrestrial photogrammetry in archaeological applications [15], in particular with measurements made on a part of the Palace of Phaistos on the island of Crete. In this case, results showed that in the recording of the data set, there were average differences of the order of a few centimeters, highlighting the superior ability of TLS applied on surfaces to describe the undulating portions of the walls of that settlement. On the other hand, recent studies have shown the advantage of SfM over TLS in the study of archaeological sites on surfaces such as petroglyphs [16].

A study comparing TLS with SfM for the evaluation of bulk densities of bulk samples [17] showed the validity of both methods with a less than $4.5 \%$ variation, but the authors of the study do not recommend either of the two methods. However, in recent modeling applications for building structures, a comparison between the two techniques has been performed on the ruins of the Church of the Annunciation of the Blessed Virgin Mary on Mount Carmel in Zagórz (Poland) [18]. Here, the authors show the advantages of the TLS technique over SfM in the following aspects: TLS needs less GCP; with SfM, the interior and exterior of the building must be processed separately (with the subsequent consumption of time spent on processing); TLS can be employed in low or no visibility situations (even at night). It should also be noted that the studies on heritage conservation used TLS to compare different methods performed with SfM, i.e., TLS was used as a control method, where $99.99 \%$ of the points have an accuracy of $1.2 \mathrm{~cm}$. Therefore, these authors considered TLS a more accurate technique than SfM [19]. This approach has also been claimed by authors comparing the two techniques for bridge inspection and monitoring [20]. Where all authors agree is that the SfM technique is cheaper than TLS. Up to now, no comparison has been made for archaeological mosaics. For this reason, this case study presents a comparison of the results of both methods, TLS and SfM, applied to a Roman mosaic for its 3D virtual re-creation.

\section{Materials and Methods}

\subsection{Mosaic of Cantillana}

The Cantilla mosaic was found in November 2017 in the village of Cantillana (Seville), Figure 1, in southern Spain. The exact coordinates were UTM ETRS89 H30 (250502.350 W, $4165806.514 \mathrm{~N}$ ), equivalent to EPSG25830. 


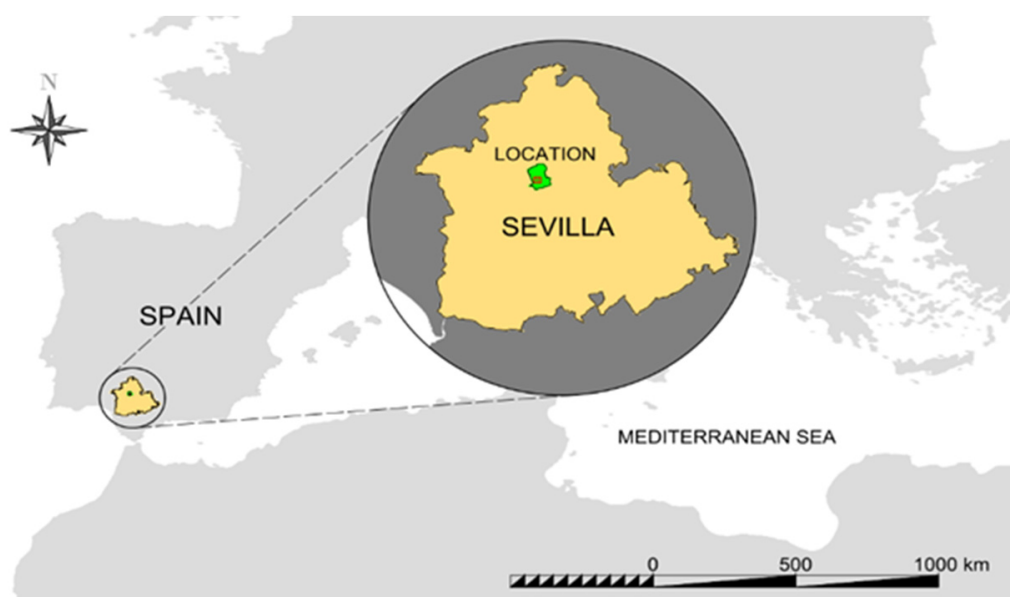

Figure 1. Location of the Mosaic of Cantillana (Spain).

The mosaic is part of the pavement of an interior courtyard of a Roman domus from the 2nd century AD. This was surrounded by an arcaded gallery, supported by columns, and there was the rim of a well, also decorated with the mosaic technique, and a marble drain for the evacuation of rainwater. The mosaic decoration represents an aquatic environment, a marine bottom with a large number of marine species with bright colors on a white background of tesserae and black lines that simulate the movement of the fish (see Figure 2).

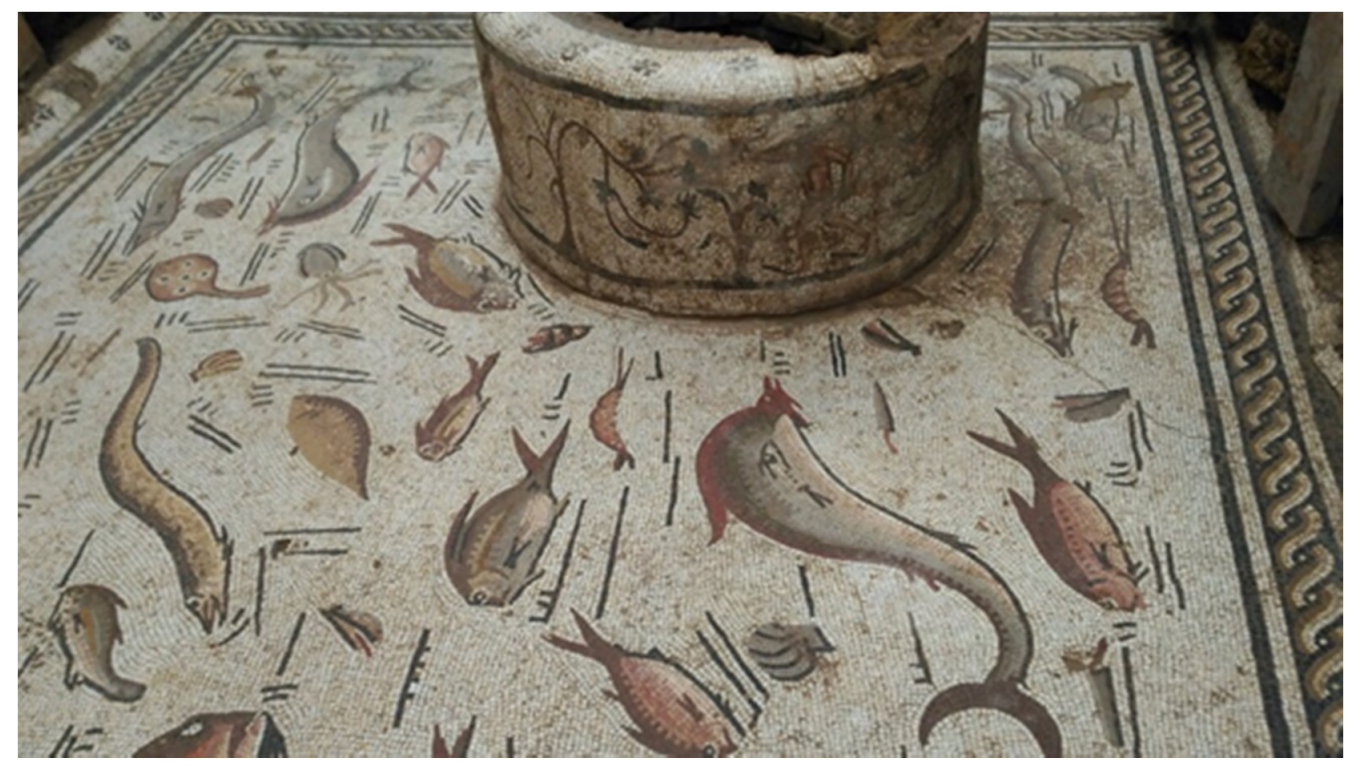

Figure 2. Detail of the Cantillana mosaic (Spain).

This mosaic, crowned by a well, is also decorated and surrounded by other structures in the Roman building to which it belongs, was extracted and restored in the Museum of Local History, where it is currently on permanent exposition until it is returned to the site where it was found after it has been adapted as an archaeological enclosure or crypt. It is, therefore, of the utmost importance to know with the utmost precision its geometry and relative positions.

\subsection{Methods}

The methods evaluated in this study, TLS and SfM, are shown in Figure 3. Previous works have been carried out for both methods, such as georeferencing and acquisition of ground control points (GCP) in the field. 


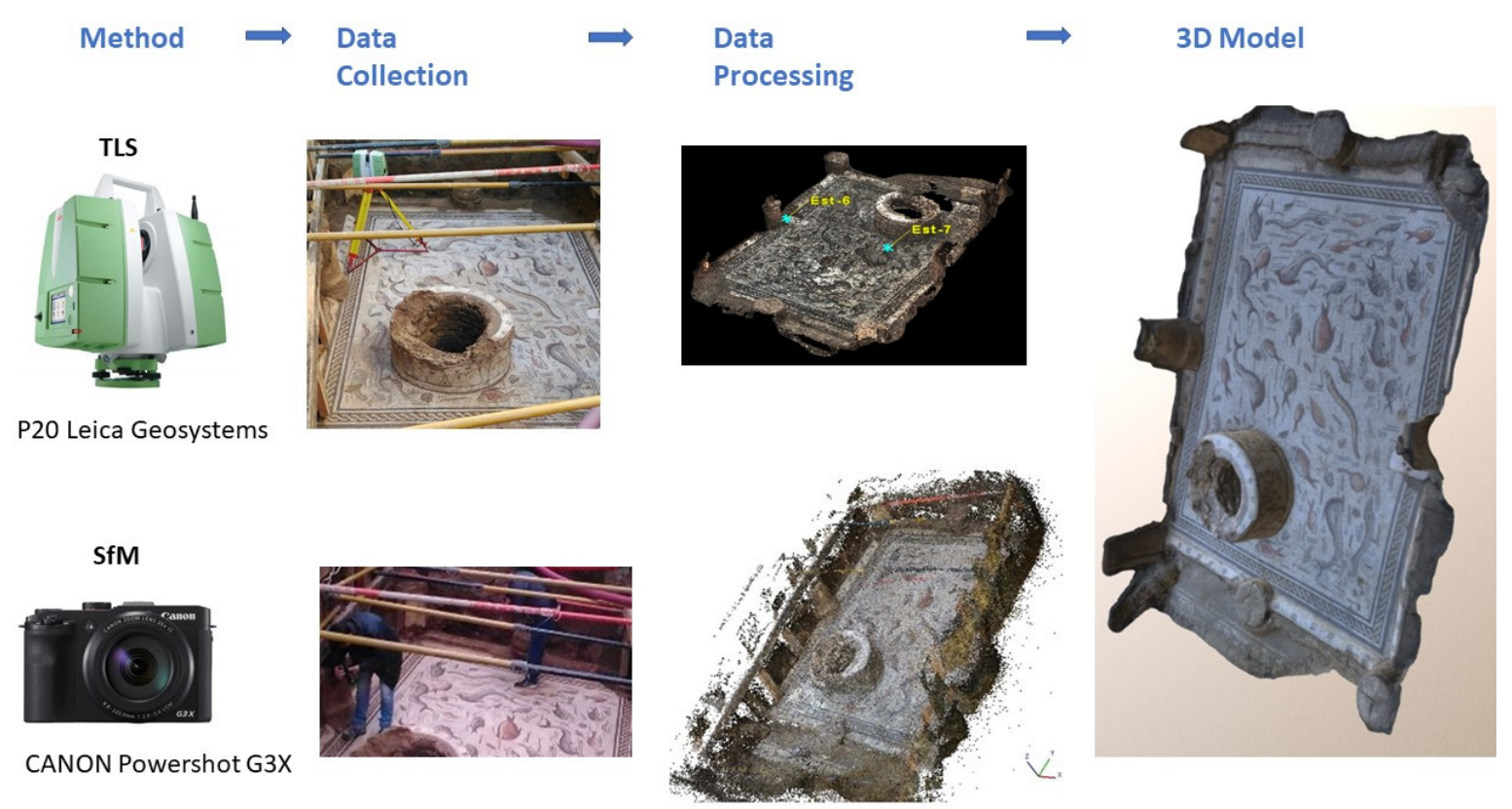

Figure 3. Methodology: TLS and SfM.

\subsubsection{Georeferencing}

Currently, all archaeological excavations must be georeferenced in order to have absolute coordinates in the official reference frame (UTM ETRS89) and to be able to proceed with their protection [21]. In this study, Leica GPS equipment, model 1200 with GX1230 antenna and RX1250 control unit on a pole, was used. The technical specifications of this equipment have been described in a previous manuscript [22].

\subsubsection{Ground Control Points (GCP)}

One of the factors that can significantly improve the quality of the results is the use of accurate and well distributed ground control points (GCP) [23]. This will allow us to properly correlate the generated model to the values of the terrain or the object. To ensure overall and internal accuracy, the location, distribution, and number of ground control points must be taken into account when establishing them in the area of interest [24].

The GCPs taken were the corners of the mosaic and significant points of some fish that appear as drawings in the mosaic, and of the well rim (see Figures 4 and 5). Table 1 lists the coordinates of the GCPs and the errors made in each of them once validated, in distance and pixel.
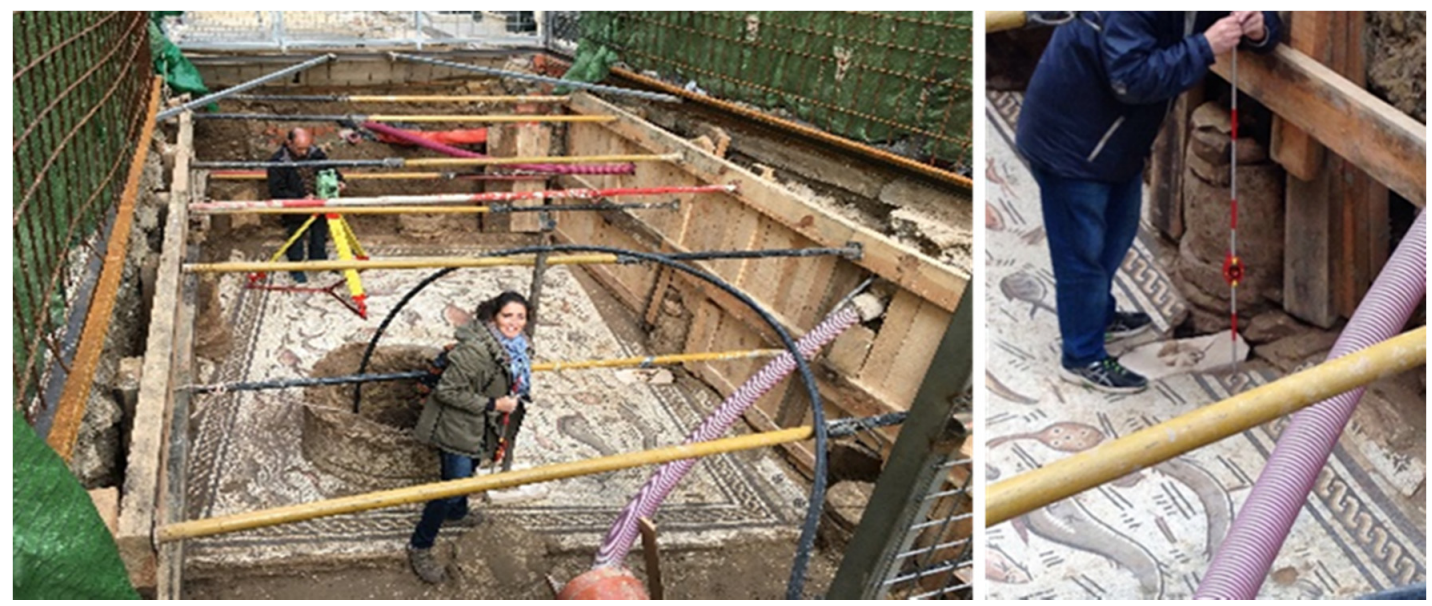

Figure 4. GCP surveying with the TCR705 total station. 

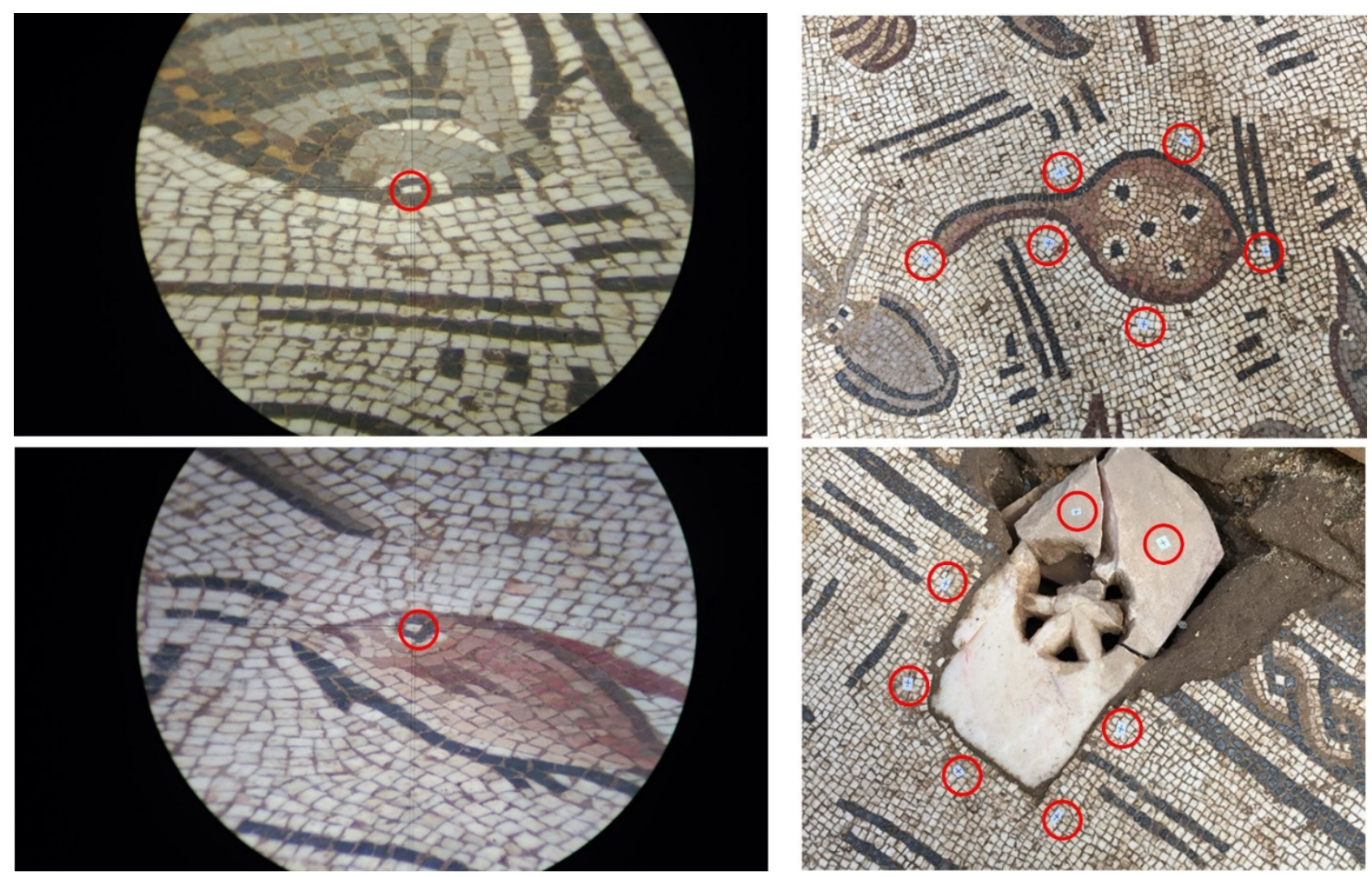

Figure 5. Example of Ground Control Points recorded (O).

Table 1. GCP Coordinates (UTM ETRS89) and errors.

\begin{tabular}{cccccc}
\hline GCP & $\mathbf{X}$ & $\mathbf{Y}$ & $\mathbf{Z}$ & $\mathbf{E}_{\text {distance }}(\mathbf{m m})$ & $\mathbf{E}_{\text {pixel }}$ \\
\hline 1 & $250,501.239$ & $4,165,808.807$ & 30.225 & 1.7 & 0.352 \\
2 & $250,503.802$ & $4,165,808.644$ & 30.201 & 0.9 & 0.285 \\
3 & $250,504.121$ & $4,165,808.976$ & 30.199 & 0.7 & 0.175 \\
4 & $250,504.042$ & $4,165,806.570$ & 30.134 & 0.6 & 0.313 \\
5 & $250,504.003$ & $4,165,805.965$ & 30.148 & 3.6 & 0.265 \\
6 & $250,503.921$ & $4,165,804.518$ & 30.208 & 1.5 & 0.424 \\
7 & $250,501.001$ & $4,165,804.747$ & 30.251 & 0.6 & 0.559 \\
8 & $250,500.937$ & $4,165,805.000$ & 30.252 & 08 & 0.308 \\
9 & $250,503.342$ & $4,165,807.727$ & 30.177 & 04 & 0.213 \\
10 & $250,501.945$ & $4,165,807.384$ & 30.204 & 04 & 0.198 \\
11 & $250,502.596$ & $4,165,806.482$ & 30.185 & 24 & 0.289 \\
12 & $250,503.031$ & $4,165,804.971$ & 30.201 & 15 & 0.463 \\
13 & $250,502.005$ & $4,165,805.997$ & 30.748 & 02 & 0.500 \\
14 & $250,502.448$ & $4,165805.860$ & 30.756 & 17 & 0.600 \\
15 & $250,502.529$ & $4,165805.234$ & 30.747 & 15 &
\end{tabular}

A total station, model Leica TCR705, of angular precision $15 \mathrm{cc}$. and $2 \mathrm{~mm}+2 \mathrm{ppm}$ linear, was used [25], (see Figure 4). The use of the total station is due to the fact that it has greater precision than the methodologies analyzed in this study, SfM and HDS. The points were marked with adhesive targets to fix with better precision the points to be taken with the mini prism (see Figure 5).

\subsubsection{Photogrammetry (SfM)}

The photographs were taken from the ground with a CANON Powershot G3X camera, focal length $8.8 \mathrm{~mm}$ and pixel size $2.4 \times 2.4$ microns. The cost of this equipment is usually around EUR 500. Data acquisition was carried out following a displacement similar to 
that used in the programming of a photogrammetric flight, i.e., nadir shots (see Figure 6), maintaining the necessary overlap both in rows and columns.
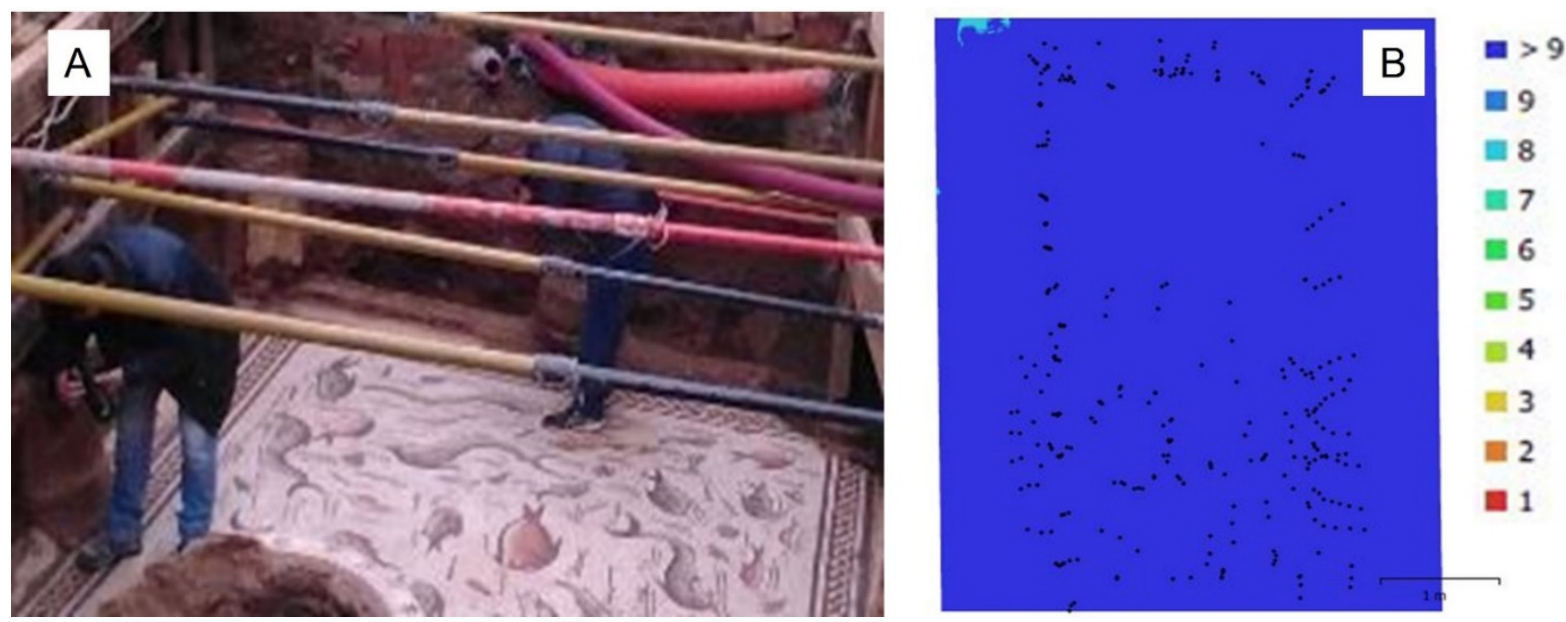

Figure 6. Data acquisition with SfM: (A) Taking photographs; (B) Overlapping of photographs.

The conditions for data collection using SfM techniques at the Cantillana site were excellent, since, due to the characteristics of the environment, there was diffuse light and consequently few shadows were produced. Likewise, the features of the object of study, due to its rough texture and varied colors, made it possible to obtain potentially high quality results. A total of 305 photos were taken within $30 \mathrm{~min}$. The result obtained was an overlap of more than $80 \%$ (see Figure 6), where the whole mosaic had an overlap of more than 9 photographs. It should be remembered that the usual structure-from-motion (SfM) techniques need, at the least, trifocal overlaps to calibrate the cameras and reconstruct a scene [26].

Once all the photos had been taken, they were dumped and processed with the Agisoft Metashape program, which is based on a series of automatic algorithms. The processing time for the 305 photos was $14 \mathrm{~h}$. Of these photos, only $15 \%$ needed technician assistance, and the others were processed automatically by the software (see Figure 7).

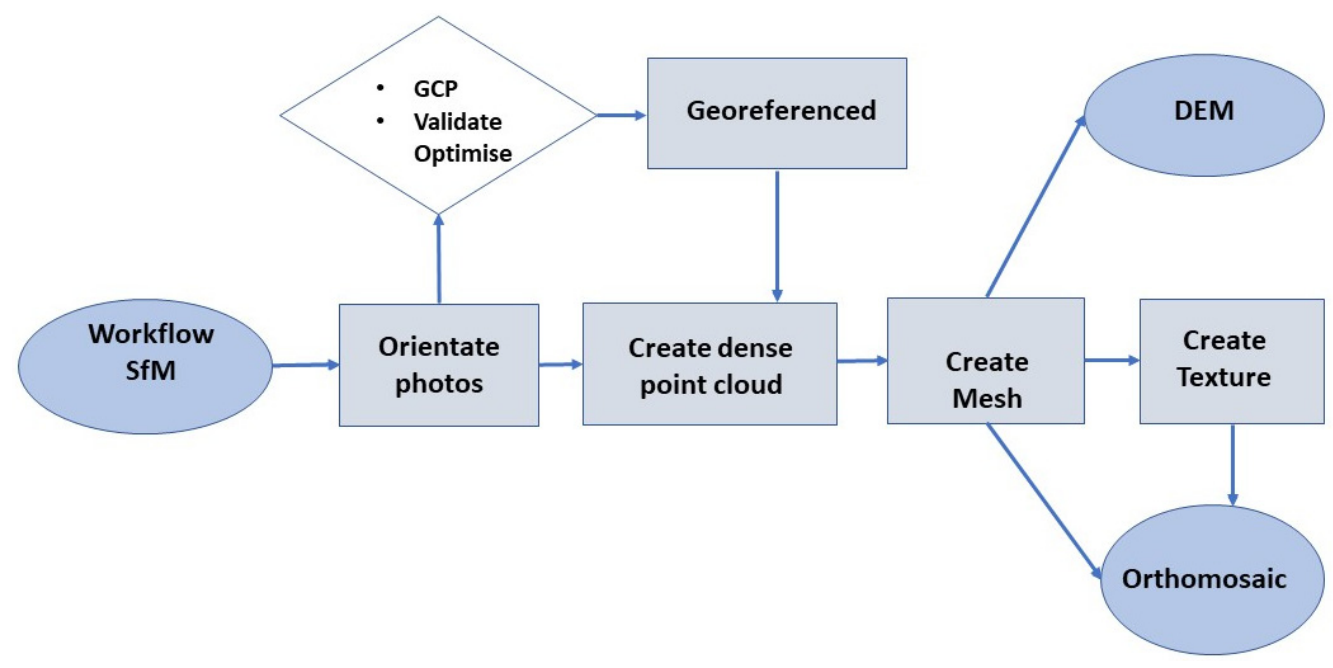

Figure 7. SfM Processing workflow.

A virtual 3D representation of the mosaic done with SfM can be found at the link https: //sketchfab.com/3d-models/mosaico-terramar-o-de-los-delfines-9d38178adae4403384f9 38cf25cbc51c (accessed on 11 December 2021). 


\subsubsection{Terrestrial Laser Scanning (TLS)}

The TLS methodology aimed to obtain 3D information of the mosaic to reconstruct the scanned object. This methodology has, a priori, a number of drawbacks in relation to accuracy. These are due to internal and external factors. The internal ones are due to the type of equipment model used [27]. The external factors are due to the type of object surface, i.e., the material itself, which mainly affects the angle of incidence of the TLS laser [28].

Laser scanners use different technologies for their performance. Some are time-offlight processors, i.e., they measure the time it takes for the emitted laser beam to travel from the scanner to the object and back, also known as pulse processors. Others work by phase difference, which implies that they have a periodic base signal which is modified depending on the object upon which it hits, and the existing modular difference between the emitted and received phase is then used to determine the distance traveled by the laser. The latest technological advances in TLS have allowed for the development of a technique called Wave Form Digitization (WFD), which is based on mixing pulse and phase difference measurement technology [29]. Lasers with WFD technology emit a multitude of pulses to record a single point, from all the records of that single point they eliminate those whose signal is very different from the majority. The signals that are optimal are added together, thus obtaining the measured point [30].

A Leica Geosystems P20 based on WFD technology with linear accuracy $\pm 1 \mathrm{~mm}$ and angular, vertical and horizontal 8 " accuracy was used in this study. This equipment is able to record between 50,000 and 1,000,000 points per second (see Figure 8). The cost of this equipment is around EUR 20,000.
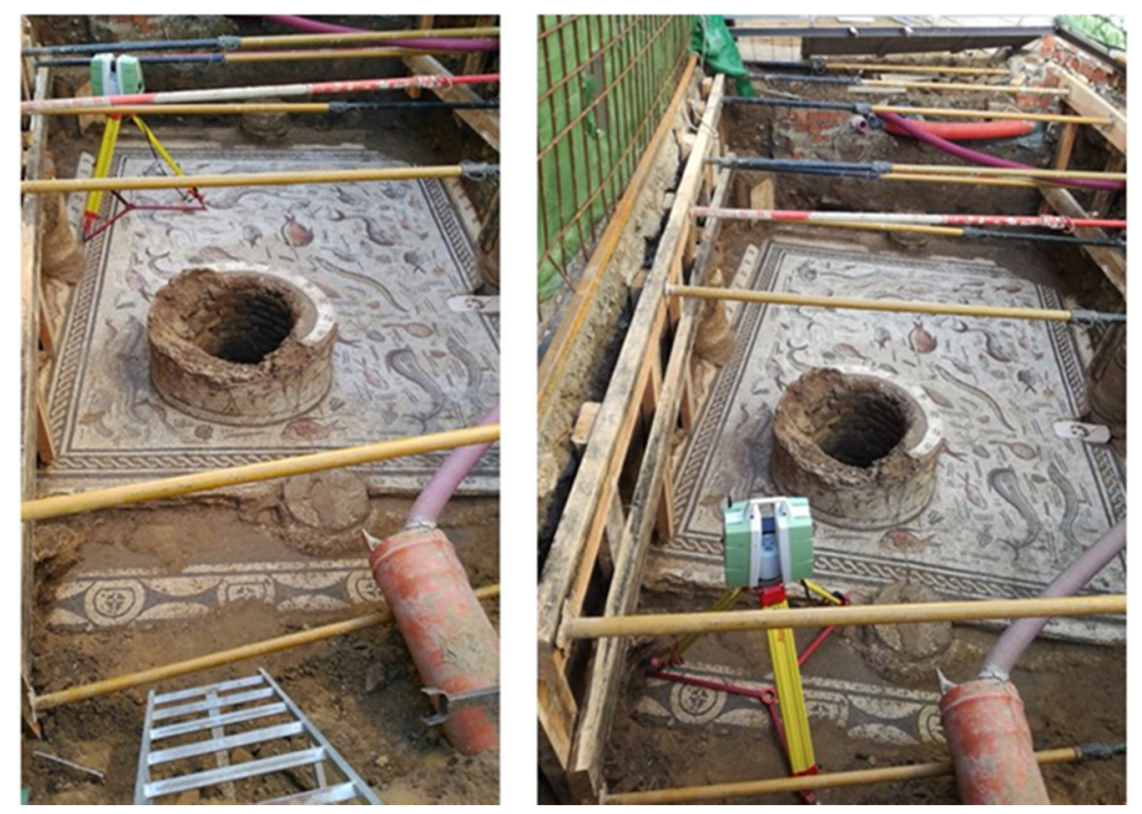

Figure 8. Data acquisition with TLS from different points of view.

There were three parking points with the TLS scanner, two inside the mosaic and one on the outside, since all the devices in the area related to the safety of the excavation, such as struts and structure fastenings to keep the mosaic as stable as possible (see Figure 8).

The TLS parking points (Est- 6 and Est-7) were at the level of the mosaic. The third scan was made from the upper part (Est-5), that is to say at the street floor level, in order to have a record from above, although a posteriori all the errors produced by the mosaic excavation support props had to be eliminated. Figure 9 shows the location of the parking lots for the three scans and that of the four targets used. The targets model GZT21, Figure 9 (D-01, D-02, D-03, D-04), were installed on their corresponding magnetic supports. The 
coordinates of these targets are listed in Table 2. The resolution was programmed to capture points at a step of $3 \mathrm{~mm}$ at $10 \mathrm{~m}$. Scanning conditions are listed in Table 3.
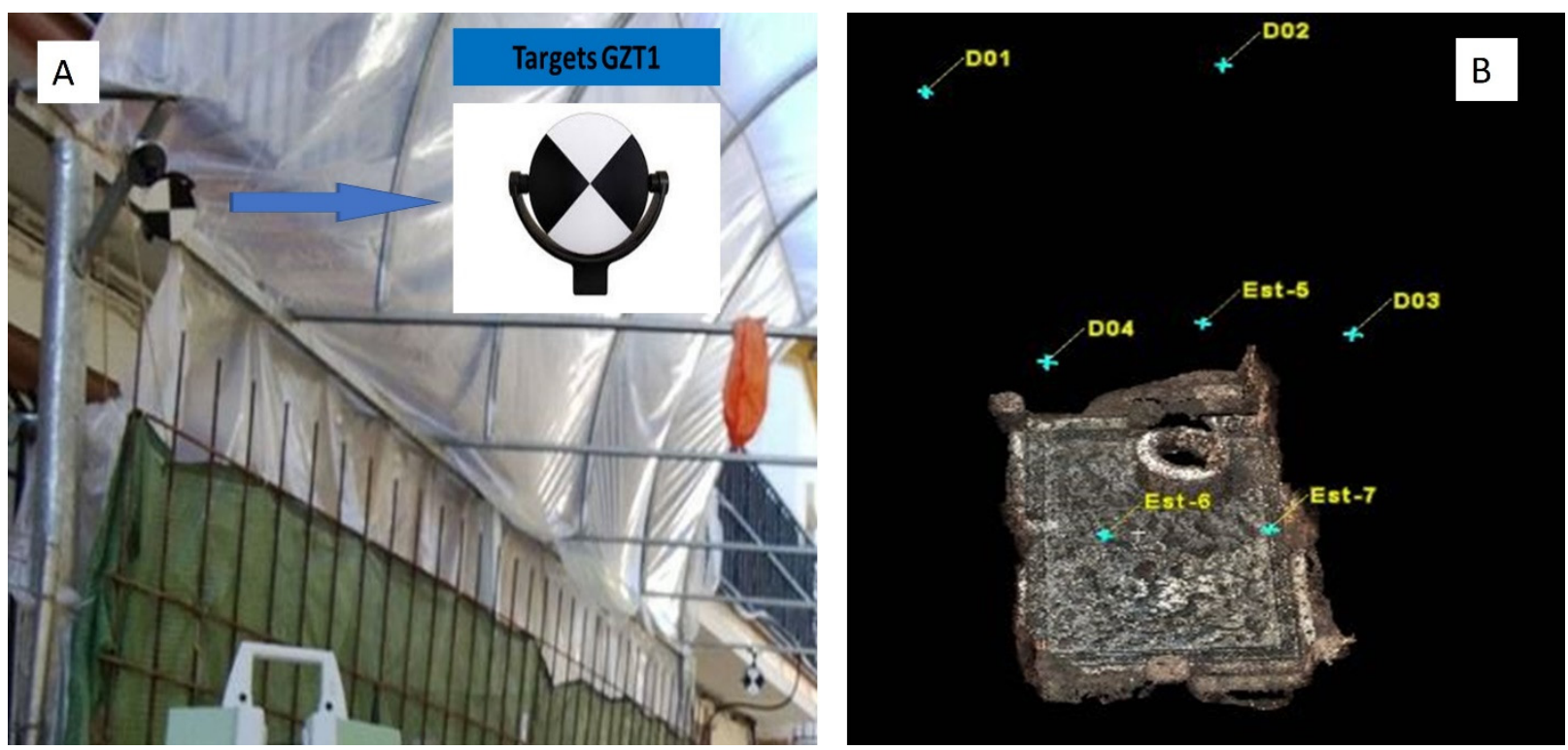

Figure 9. Target: (A) Target example; (B) Target positions.

Table 2. Coordinates of targets: D-01, D-02, D-03, D-04.

\begin{tabular}{cccc}
\hline Target & X & Y & Z \\
\hline D01 & $250,504.887$ & $4,165,802.485$ & 34.710 \\
D02 & $250,501.280$ & $4,165,802.133$ & 34.706 \\
D03 & $250,500.799$ & $4,165,807.835$ & 34.615 \\
D04 & $250,503.795$ & $4,165,808.125$ & 34.728 \\
\hline
\end{tabular}

Table 3. Scanning conditions.

\begin{tabular}{cc}
\hline Parameter & Value \\
\hline Field of view & Full vault \\
Hz/V Area $\left(^{\circ}\right)$ & $90^{\circ} / 55^{\circ}$ \\
Scan Mode & Scan Only \\
Resolution & $25.0 \mathrm{~mm} @ 10 \mathrm{~m}$ \\
Quality & 3 \\
Number of Dots $(\mathrm{Hz} \times \mathrm{V})$ & $2514 \times 1013$ \\
Image Exposure & Auto \\
White Balance & Cold Light \\
Image Resolution & $1920 \times 1920$ \\
HDR Image & No \\
Estimated Time & 7 min $22 \mathrm{~s}$ \\
\hline
\end{tabular}

Once the point acquisition was finished, the points were loaded into Leica's Cyclone program. This software merges the point clouds taken from the different positions with the support of the control points, i.e., the four targets already mentioned. After all the data had been grouped into a single point cloud and correctly georeferenced, it was exported in a format readable by other programs to allow for its management and analysis. 


\section{Results}

\section{1. $S f M$}

The dense point cloud obtained with SfM were 8,246,650 points with RGB (Red, Green, Blue) color. The results achieved with photogrammetry were: a dense point cloud (see Figure 10A), mesh without texture (see Figure 10B), mesh with texture (see Figure 10C), and a digital elevation model (see Figure 10D). A virtual 3D representation of the mosaic done with SfM can be found at the link https:/ /sketchfab.com/3d-models/mosaico-terramar-ode-los-delfines-9d38178adae4403384f938cf25cbc51c (accessed on 11 December 2021).
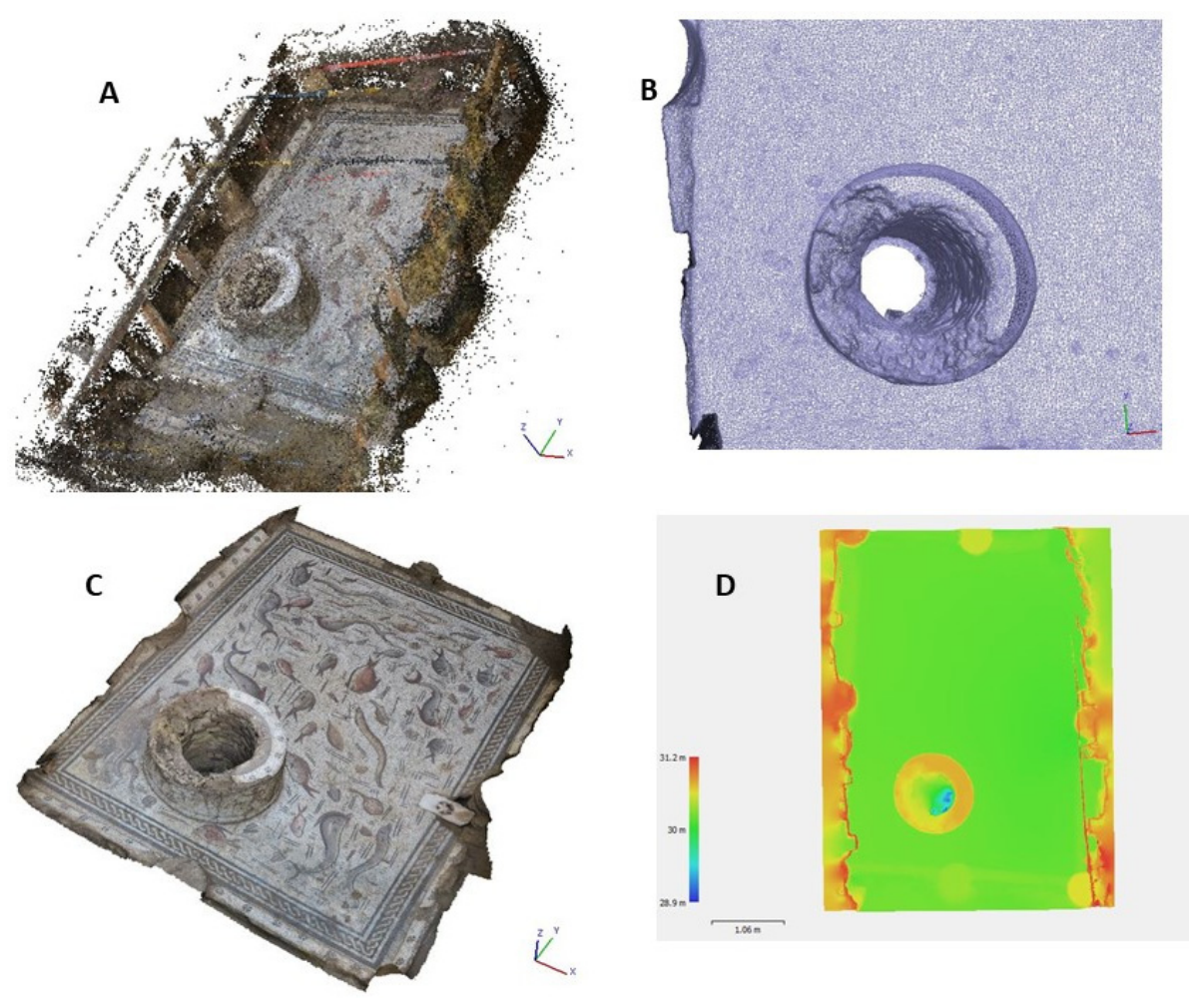

Figure 10. Results from SfM (A-D).

\subsection{TLS}

A cloud of 99,821 points with RGB (Red, Green, Blue) color was obtained with the TLS once the scanning area was completed (see Figure 11). A virtual 3D representation of the mosaic done with TLS can be found at the link https://www.pointbox.xyz/clouds/61 b1d56d99e6e097d35c48ba (accessed on 11 December 2021).

\subsection{SfM vs. TLS}

Figure 12 shows an overlay between the 3D model generated by SfM and the point cloud obtained with TLS (in red). It reveals areas in which there is no representation of the points obtained with TLS or, more precisely, that they remain hidden under the SfM model. It is observed in Figure 12 that all the points measured by TLS on the smooth marble surface corresponding to the sump of the mosaic are not shown in the model. Figure 13A shows an enlargement of this area. Figure 13B shows an elevation showing that the points taken with TLS are located below the model, with GCP406 located on the surface of the sink as a reference. 


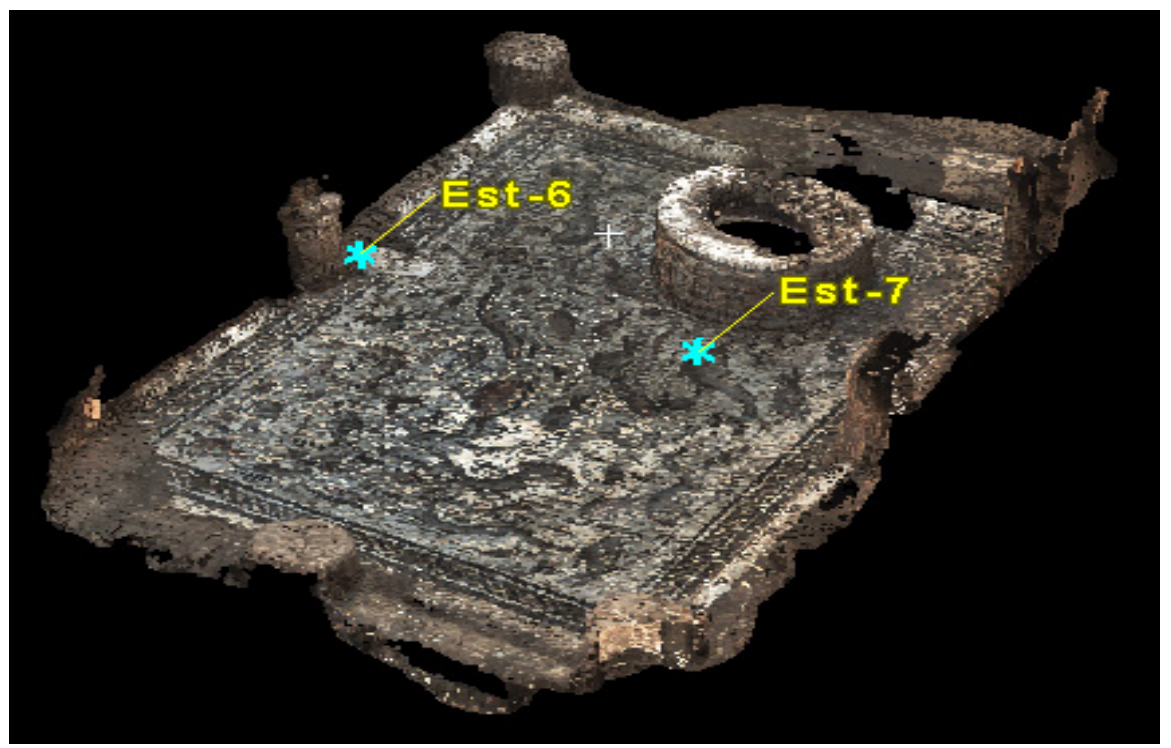

Figure 11. Point cloud obtained with TLS.

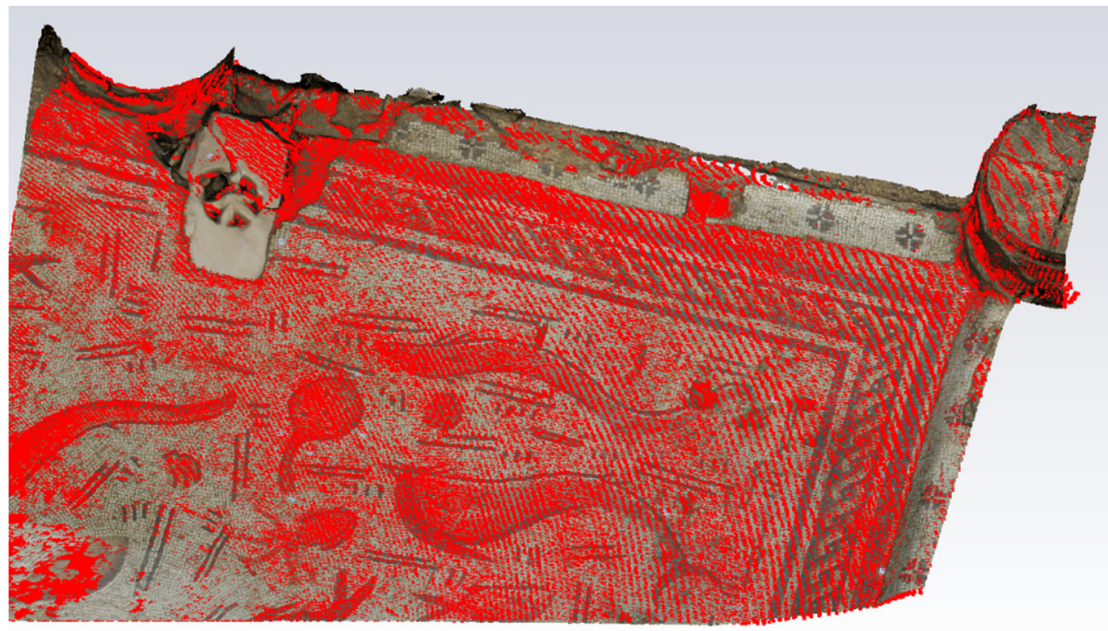

Figure 12. SfM model vs. TLS point cloud.
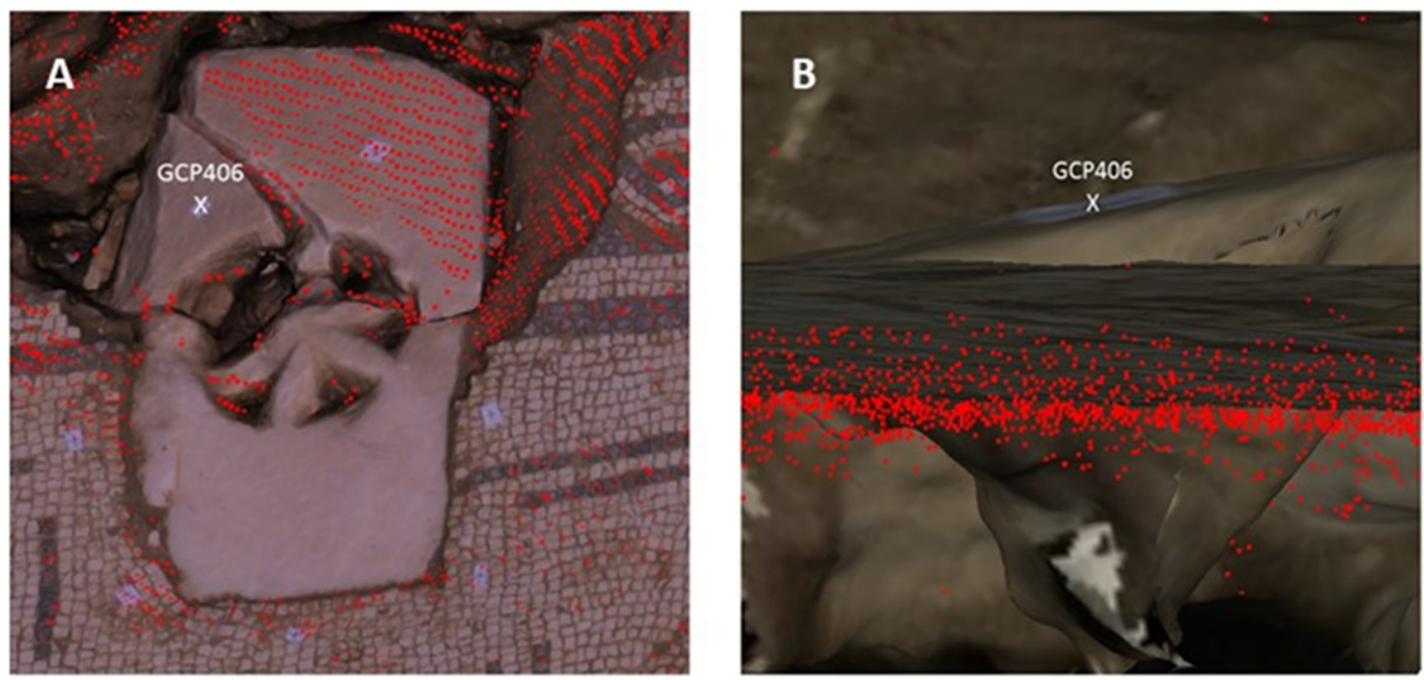

Figure 13. TLS points representation on SfM model on marble sink area. (A) 2D representation; (B) Altimetric profile. 
It is clear that there is a difference in elevation in several areas, so it was considered necessary to perform a control measurement using a method that was not influenced by materials or geometric layout. For this purpose, the same TCR705 total station used for the georeferencing of the model was used. This total station was used to measure points of the mosaic with the help of a mini prism, so that the orientation or characteristics of the materials would not affect the measurement in any case. A total of 233 points were taken with a wide variety in location, material, degree of inclination, and color, due to the difference between shades represented in the tesserae of the mosaic. This method offered an accuracy within the range provided by the total station used, i.e., $\pm 2 \mathrm{~mm}+2 \mathrm{ppm}$.

The comparison was made with a selected reduced area of the mosaic, (see Figure 13), which contains all the elements where the main divergences were found (sump, baseboard, etc.).

To obtain the required area from the data obtained with TLS, the area of interest was simply cut out of the point cloud obtained from the whole mosaic. In order to present the chosen mosaic area with SfM, a new project with a total of 69 photographs was made. Of the 233 GCPs measured with the total station, 18 were used, as they were marked with stickers, so that identification was quick and accurate in the photographs (see Figure 14).

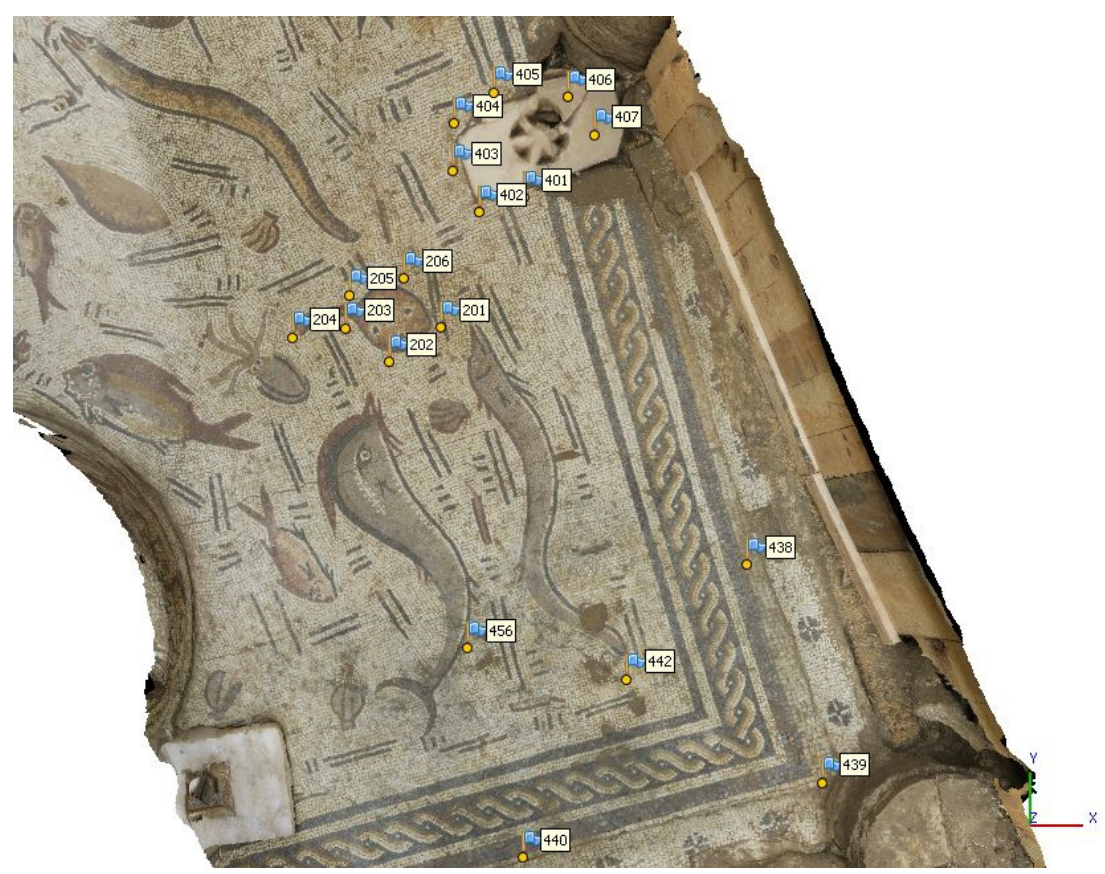

Figure 14. SfM model of the selected area with GCPs represented.

\section{Discussion}

The 3DReshaper software was used to analyze the accuracy of the points between TLS and SfM. Figure 15 shows a comparison between both models analyzed, where $96 \%$ of the points presented an error in the range of $+3 \mathrm{~mm}$ to $-5 \mathrm{~mm}$ (see Figure 15). The other $3.8 \%$ of the points varied within a range of $-5 \mathrm{~mm}$ and $-17 \mathrm{~mm}$. These results are not a priori relevant and need to be compared with more precise data, such as the GCP taken with a total station. 


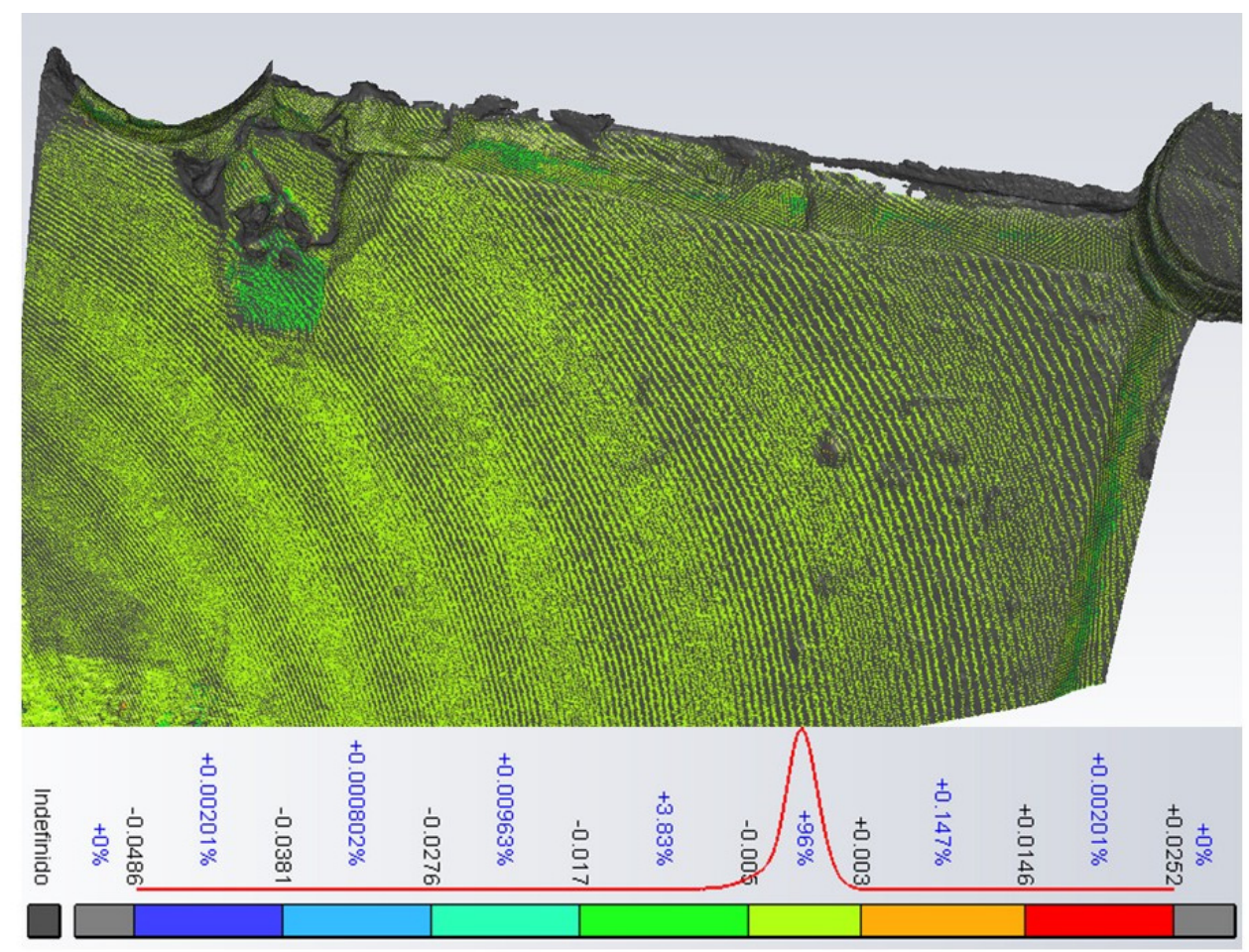

Figure 15. TLS vs. SfM.

The analysis of the SfM with the GCPs using 3DReshaper is shown in Figure 16A. The results show that the points had an absolute error greater than $1 \mathrm{~mm}$, and that in no cases did the error reach $2 \mathrm{~mm}$. Considering the features of the total station used to take the control points, where the error range is $\pm 2 \mathrm{~mm}+2 \mathrm{ppm}$ in the determination of coordinates, it can be concluded that the errors are below those seen in the reference materials.

By superimposing the GCPs on the high-definition mesh generated from the TLS points, it can be observed in Figure 16B that $88.5 \%$ of the points have an error between $5 \mathrm{~mm}$ and $-0.7 \mathrm{~mm}$, while only $2.39 \%$ are between $-0.7 \mathrm{~mm}$ and $-2 \mathrm{~mm}$. In addition, $9.17 \%$ of the points were between $5 \mathrm{~mm}$ and $13 \mathrm{~mm}$. In this section, it can be observed that these are the points of the marble sink. The cyan and red tones are where the largest range of errors (between $5 \mathrm{~mm}$ and $1 \mathrm{~cm}$ ) have appreciated, and it is there where the biggest differences can be observed, likely because of the materials that compose the sump, such as marble. The green tones of the baseboard are due to the angle of incidence, which in the baseboard is different from the rest of the points of the mosaic.

Table 4 summarizes the error ranges of each method regarding the control points. It can be observed that the technique that obtains the best results with respect to the GCPs is SfM photogrammetry. This does not mean that the TLS method does not meet the expectations of the GCPs, but that in the range of $<2 \mathrm{~mm}$, the percentage of points is higher. In addition, it was found that there is a significant percentage of points that exceed the threshold of $\geq 5 \mathrm{~mm}$, in particular $9.17 \%$, because they are points taken on the clean part of the sink. The increase in error in this area is due to the material from which the sink is composed, which is marble. It has been proven in the literature that the laser in materials such as marble, goes through part of the surface and generates erroneous information in the points measured [31]. Specifically, marble, being a porous material on its surface, causes the laser to pass through the surface, generating an error in the altimetry of the points. 

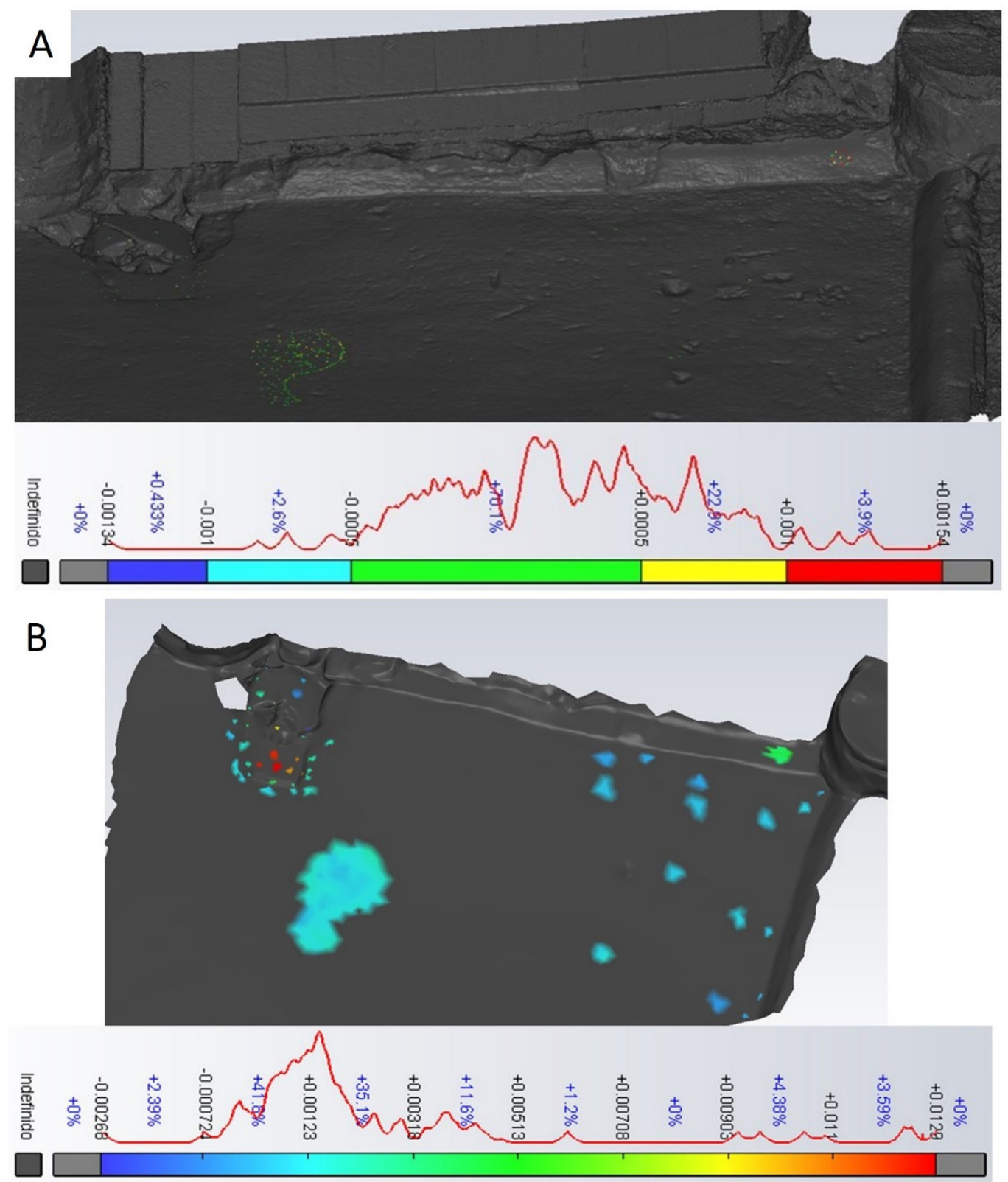

Figure 16. Accuracy analysis. (A) GCP vs. SfM. (B) GCP vs. TLS.

Table 4. Absolute range of error.

\begin{tabular}{lccccc}
\hline & $\geq \mathbf{5} \mathbf{~ m m}$ & $<5 \mathbf{~ m m}$ & $<\mathbf{~} \mathbf{m m}$ & $<\mathbf{~} \mathbf{m m}$ & $<0.5 \mathbf{~ m m}$ \\
\hline GCP vs. SfM & - & - & $4.3 \%$ & $95.6 \%$ & $70.1 \%$ \\
\hline GCP vs. TLS & $9.17 \%$ & $88.5 \%$ & $2.39 \%$ & - & - \\
\hline
\end{tabular}

\section{Conclusions}

In this research, two geomatics techniques have been compared for the study of a Roman mosaic in its original location for its transfer to a restoration area or museum, and with the possibility of it being relocated in the future back to its original location. In the present study, photogrammetry based on SfM and low-cost cameras, and terrestrial scanner or TLS have been used, which are very widespread in archaeological excavations due to the high precision obtained from their results and the massive collection of point clouds. These have been compared with a more accurate method of obtaining coordinates, but that 
is limited in terms of production or amount of information, i.e., the total station, which has, therefore, served as a control method.

In particular, it was observed that the marble area, that of the sink, was the one area that was influenced the most in the data acquisition with TLS, obtaining points below the elevation determined by the total station, probably because the porosity of the material produced a slight delay in the reflection of the signal emitted by the scanner. It can be concluded that the SfM technique is the one that comes closest to the optimal values generated by the total station. This is not to say that TLS is not an accurate technique since its accuracy values are very close.

In addition, the experiments performed in this study demonstrated the higher performance level and simplicity of the SfM technique with respect to TLS performance. In addition, the SfM technique is accessible to non-specialized personnel as it involves taking photographs using a certain strategy but without the need for technical preparation. The TLS technique, on the other hand, requires several stations and the measurement of control points from all stations. When equipment costs are considered alongside these factors, where the TLS technique is 40 times more expensive, but the SfM obtained 10 times more points, photogrammetry techniques with SfM presented a clear advantage over TLS for the accurate documentation of mosaics in archaeological excavations.

However, there are constraints to the technique of photogrammetry using SfM if it is to be extended to other types of archaeological excavations, e.g., when the distance at which the photographs are taken is not close to the object. In this case, the distance would be the equivalent to the flight altitude of a photogrammetric flight. Another important limitation is when environmental lighting conditions are not suitable; here, the TSL technique is clearly better, for example, in caves or inside buildings.

Author Contributions: Conceptualization, F.M.-A. and C.M.-B.; methodology, A.M.P.-R.; M.J.L.-B.; R.M.-Á.; J.C.M.-G.; F.M.-A. and C.M.-B.; software, C.M.-B. and A.M.P.-R.; validation, C.M.-B. and A.M.P.-R.; formal analysis, C.M.-B. and A.M.P.-R.; data curation, J.C.M.-G.; C.M.-B. and A.M.P.-R.; writing-original draft preparation, F.M.-A., C.M.-B. and A.M.P.-R.; writing-review and editing, A.M.P.-R.; M.J.L.-B.; R.M.-Á.; J.C.M.-G.; F.M.-A. and C.M.-B.; supervision, F.M.-A.; project administration C.M.-B. and A.M.P.-R.; funding acquisition, C.M.-B. and A.M.P.-R. All authors have read and agreed to the published version of the manuscript.

Funding: This research received no external funding.

Institutional Review Board Statement: Not applicable.

Informed Consent Statement: Not applicable.

Data Availability Statement: Not applicable.

Acknowledgments: The authors would like to thank CIAIMBITAL (University of Almeria, CeiA3) for its support.

Conflicts of Interest: The authors declare no conflict of interest.

\section{References}

1. Marín-Buzón, C.; Pérez-Romero, A.; López-Castro, J.; Ben Jerbania, I.; Manzano-Agugliaro, F. Photogrammetry as a new scientific tool in archaeology: Worldwide research trends. Sustainability 2021, 13, 5319. [CrossRef]

2. Cheng, L.; Chen, S.; Liu, X.; Xu, H.; Wu, Y.; Li, M.; Chen, Y. Registration of laser scanning point clouds: A review. Sensors 2018, 18, 1641. [CrossRef] [PubMed]

3. Liang, X.; Kankare, V.; Hyyppä, J.; Wang, Y.; Kukko, A.; Haggrén, H.; Yu, X.; Kaartinen, H.; Jaakkola, A.; Guan, F.; et al. Terrestrial laser scanning in forest inventories. ISPRS J. Photogramm. Remote Sens. 2016, 115, 63-77. [CrossRef]

4. Large, A.R.G.; Heritage, G.L.; Charlton, M.E. Laser scanning: The future. Laser Scanning Environ. Sci. 2009, $262,262-271$. [CrossRef]

5. Gressin, A.; Mallet, C.; Demantké, J.; David, N. Towards 3D lidar point cloud registration improvement using optimal neighborhood knowledge. ISPRS J. Photogramm. Remote Sens. 2013, 79, 240-251. [CrossRef]

6. Yang, B.; Dong, Z.; Liang, F.; Liu, Y. Automatic registration of large-scale urban scene point clouds based on semantic feature points. ISPRS J. Photogramm. Remote Sens. 2016, 113, 43-58. [CrossRef] 
7. Weinmann, M.; Hinz, S.; Jutzi, B. Fast and automatic image-based registration of TLS data. ISPRS J. Photogramm. Remote Sens. 2011, 66, S62-S70. [CrossRef]

8. Puttonen, E.; Lehtomäki, M.; Kaartinen, H.; Zhu, L.; Kukko, A.; Jaakkola, A. Improved sampling for terrestrial and mobile laser scanner point cloud data. Remote Sens. 2013, 5, 1754-1773. [CrossRef]

9. Kang, D.; Lee, H.; Park, H.S.; Lee, I. Computing method for estimating strain and stress of steel beams using terrestrial laser scanning and FEM. In Key Engineering Materials; Trans Tech Publications Ltd.: Freienbach, Switzerland, 2007; Volume 347, pp. 517-522. [CrossRef]

10. Brechtken, R.; Przybilla, H.J.; Wahl, D. Visualisation of a necropolis on the basis of a portable aerial photogrammetric system and terrestrial laser scanning. In Proceedings of the ISPRS Congress Beijing 2008, Beijin, China, 3-11 July 2008; Volume XXXVII, pp. 667-672. Available online: https://www.researchgate.net/profile/Rainer-Brechtken/publication/242142584_ VISUALISATION_OF_A_NECROPOLIS_ON_THE_BASIS_OF_A_PORTABLE_AERIAL_PHOTOGRAMMETRIC_SYSTEM_ AND_TERRESTRIAL_LASER_SCANNING/links/5e4bbde6a6fdccd965af1d57/VISUALISATION-OF-A-NECROPOLIS-ONTHE-BASIS-OF-A-PORTABLE-AERIAL-PHOTOGRAMMETRIC-SYSTEM-AND-TERRESTRIAL-LASER-SCANNING.pdf (accessed on 11 December 2021).

11. Boochs, F.; Kern, F.; Schütze, R.; Marbs, A. Approaches for geometrical and semantic modelling of huge unstructured 3D point clouds. Photogramm. Fernerkund. Geoinf. 2009, 2009, 65-77. [CrossRef]

12. Lerma, J.L.; Navarro, S.; Cabrelles, M.; Villaverde, V. Terrestrial laser scanning and close range photogrammetry for 3D archaeological documentation: The Upper Palaeolithic Cave of Parpalló as a case study. J. Archaeol. Sci. 2010, 37, 499-507. [CrossRef]

13. Grussenmeyer, P.; Landes, T.; Alby, E.; Carozza, L. High resolution 3D recording and modelling of the Bronze Age cave “Les Fraux" in Périgord (France). In Proceedings of the Conference ISPRS Commission V Symposium, Newcastle, UK, 2020; Volume 38, pp. 262-267. Available online: https:/ / hal.archives-ouvertes.fr/hal-03099460/file/ISPRS_2010_Gruss_Land_Alb_Carozza.pdf (accessed on 11 December 2021).

14. Lichti, D.D.; Gordon, S.J.; Stewart, M.P.; Franke, J.; Tsakiri, M. Comparison of digital photogrammetry and laser scanning. In Proceedings of the Proceedings: CIPA W6 International Workshop, Corfu, Greece, 1-2 September 2002; pp. $39-47$.

15. Fabris, M.; Achilli, V.; Artese, G.; Bragagnolo, D.; Menin, A. High resolution survey of phaistos palace (Crete) by Tls and terrestrial photogrammetry. Int. Arch. Photogramm. Remote Sens. Spat. Inf. Sci. 2012, 39, B5. [CrossRef]

16. Peña-Villasenín, S.; Gil-Docampo, M.; Ortiz-Sanz, J. Professional SfM and TLS vs a simple SfM photogrammetry for 3D modelling of rock art and radiance scaling shading in engraving detection. J. Cult. Heritage 2018, 37, 238-246. [CrossRef]

17. Blistan, P.; Jacko, S.; Kovanič, L'.; Kondela, J.; Pukanská, K.; Bartoš, K. TLS and SfM approach for bulk density determination of excavated heterogeneous raw materials. Minerals 2020, 10, 174. [CrossRef]

18. Lewińska, P.; Róg, M.; Żąłło, A.; Szombara, S. To save from oblivion: Comparative analysis of remote sensing means of documenting forgotten architectural treasures-Zagórz Monastery complex, Poland. Measurement 2021, 13, 110447. [CrossRef]

19. Moyano, J.; Nieto-Julián, J.E.; Bienvenido-Huertas, D.; Marín-García, D. Validation of close-range photogrammetry for architectural and archaeological heritage: Analysis of point density and 3d mesh geometry. Remote Sens. 2020, 12, 3571. [CrossRef]

20. Mohammadi, M.; Rashidi, M.; Mousavi, V.; Karami, A.; Yu, Y.; Samali, B. Quality evaluation of digital twins generated based on UAV photogrammetry and TLS: Bridge case study. Remote Sens. 2021, 13, 3499. [CrossRef]

21. Verhoeven, G.; Doneus, M.; Briese, C.; Vermeulen, F. Mapping by matching: A computer vision-based approach to fast and accurate georeferencing of archaeological aerial photographs. J. Archaeol. Sci. 2012, 39, 2060-2070. [CrossRef]

22. Méndez, V.; Pérez-Romero, A.; Sola-Guirado, R.; Miranda-Fuentes, A.; Manzano-Agugliaro, F.; Zapata-Sierra, A.; Rodríguez-Lizana, A. In-field estimation of orange number and size by 3D laser scanning. Agronomy 2019, 9, 885. [CrossRef]

23. Villanueva, J.K.S.; Blanco, A.C. Optimization of ground control point (GCP) configuration for unmanned aerial vehicle (UAV) survey using structure from motion (SFM). Int. Arch. Photogramm. Remote Sens. Spat. Inf. Sci. 2019, 42. [CrossRef]

24. Oniga, V.-E.; Breaban, A.-I.; Pfeifer, N.; Chirila, C. Determining the suitable number of ground control points for UAS images georeferencing by varying number and spatial distribution. Remote Sens. 2020, 12, 876. [CrossRef]

25. Marín-Buzón, C.; Pérez-Romero, A.; Tucci-Álvarez, F.; Manzano-Agugliaro, F. Assessing the orange tree crown volumes using google maps as a low-cost photogrammetric alternative. Agronomy 2020, 10, 893. [CrossRef]

26. Salaun, Y.; Marlet, R.; Monasse, P. Line-Based Robust SfM with Little Image Overlap. In Proceedings of the 2017 International Conference on 3D Vision (3DV), Qingdao, China, 10-12 October 2017; pp. 195-204.

27. Cabo, C.; Del Pozo, S.; Rodríguez-Gonzálvez, P.; Ordóñez, C.; Aguilera, S.D.P. Comparing terrestrial laser scanning (TLS) and wearable laser scanning (WLS) for individual tree modeling at plot level. Remote Sens. 2018, 10, 540. [CrossRef]

28. Marčiš, M. Quality of 3D models generated by SFM technology. Slovak J. Civ. Eng. 2013, 21, 13-24. [CrossRef]

29. Truong-Hong, L.; Gharibi, H.; Garg, H.; Lennon, D. Equipment considerations for terrestrial laser scanning for civil engineering in urban areas. J. Sci. Res. Rep. 2014, 3, 2002-2014. [CrossRef]

30. Large, A.R.; Heritage, G.L. Laser scanning-Evolution of the discipline. In Laser Scanning for the Environmental Sciences; WileyBlackwell: Oxford, UK, 2009; pp. 1-20.

31. Lerma García, J.L.; Van Genechten, B.; Santana Quintero, M. 3D Risk Mapping. Theory and Practice on Terrestrial Laser Scanning. Training Material Based on Practical Applications; Universidad Politecnica de Valencia Editorial: Valencia, Spain, 2008; Available online: https: / / lirias.kuleuven.be/1773517?limo=0 (accessed on 11 December 2021). 